\title{
Public Attitudes to Primary Care Reform
}

In contemplating this column on primary care reform, many things came to mind. First was an anecdote from a friend of mine who comes from a small town where people frequently greet each other with the salutation, "What do you know for sure?" The standard response is, "Pretty quiet."I think that anecdote probably best sums up how the public generally responds to primary care reform at the present time.

Primary care reform has never achieved the public profile that it deserves, given its strategic importance, for many reasons. The main reason is that consumers express higher satisfaction over the care they receive in a doctor's office than any other type of care. In addition, consumers also tend to believe that the care they receive in a doctor's office has been cushioned from government or system cutbacks or constraint to the greatest extent. As a result, there is some confusion among the public regarding why this relationship appears to be a priority for reform when they perceive there to be a continued set of challenges in funding and enhancing the kinds of emergency care and acute care that are delivered in hospitals.

In a survey taken this spring, POLLARA asked a nationally representative sample of 2,200 Canadians to say, in their own words, what the most important healthcare issue facing the country was. No one mentioned primary care. Not a single, solitary person. Hospital food made the list, but not primary care. Instead, people are still focused on system issues associated with funding constraints - staff shortages and waiting lists.

In a number of surveys over the past five years, an increasing majority of Canadians report support for a move "away from hospital care to less expensive forms of care in the community." This has given clear direction to advocates of community-based care, home care and primary care reform. It is important to keep in mind, however, that more than three-quarters of Canadians continue to express strong preference for increased funding for emergency care and the kind of acute care that is delivered in hospitals - putting these categories higher on the priority list than virtually any other possibility for funding.

Despite all this, the public is solidly behind the aims and objectives of the kinds of primary care reform taking place in a number of jurisdictions. In particular, there is support for the idea that health maintenance in the form of regular check-ups and the first point of contact should be delivered outside of the traditional hospital setting.

People support, in large numbers, the idea that their healthcare should be coordinated across the healthcare system. The lack of coordination and information sharing is something that people find surprising and troubling in this day and age. The idea of "one-stop shopping" where a patient can access a number of different health services and practitioners is also appealing to many people.
The public also supports the upside of "rostering," that is, the availability of care 24 hours a day, seven days a week. In some respects, it reminds people of the old country doctor who would be awakened in the middle of the night to tend to a severe illness in the family. They do not necessarily want to see a return to the other condition present in those times - absence of a choice or a second opinion. But the "question" of choice is not a major priority with the public at the present time. Repairing and improving elements of the system where choice has become irrelevant waiting lists and staff shortages in acute care and emergency care settings - is the main priority.

The idea of a contract between provider and consumer is also popular with many people. It is seen as leading to increased accountability. But herein also lies the challenge. We indicated above that choice is not a major priority for the public in healthcare at the present time. In today's post-consumer society, people have become accustomed to informed shopping for virtually every good or service to seek the best value. As readers know, this is increasingly the case in the field of healthcare. For these consumers, the freedom to make choices between alternatives is the only kind of accountability that they know and trust, in a world where disappointment is the rule of a consumer marketplace.

The application of this approach to healthcare poses a strong challenge to new models of primary care reform that ask consumers to place all of their trust in one provider. Building trust in new delivery models will be key to short-term acceptance and adoption and long-term success.

Many jurisdictions have made a good start by positioning new primary care ventures as being initiated by providers. The message is that these physicians have found a better idea for delivering healthcare that will allow them to devote more individualized attention to patients and also have greater influence on planning and prevention. This is a much more effective, and credible, starting point for the public than a government-led venture, which would inevitably raise concerns about whether this was yet another cost-cutting exercise, particularly in the new economic and fiscal circumstances facing governments since September 11.

Don Guy is Senior Vice-President with POLLARA Inc. For questions or comments about this column, or similar matters, he may be contacted at 1-888-POLLARA or dguy@pollara.ca

This information is provided by the kind permission of the Ontario Hospital Association (OHA). The OHA subscribes to POLLARA consumer research to provide its members with a snapshot of public concerns with the healthcare system and the hospital sector. 